\title{
Interleukin-6 is a determinant of PAI-I levels in diabetic subjects with the 4G allele at position -675 of the PAI-I gene
}

\section{Dear Sir,}

Several studies have demonstrated that the levels of plasminogen activator inhibitor type 1 (PAI-1) and of inflammatory mediators, such as interleukin-6 (IL-6), are increased in type 2 diabetes (1). It is well assessed that IL-6 plays a pivotal role in diabetes as it predicts the development of the disease. It is correlated to some features of metabolic syndrome and it is involved in the pathogenesis of atherosclerosis (2). Although it is known that some proinflammatory cytokines are able to stimulate PAI-1 production, the effect of IL-6 on PAI- 1 is not clear, and contradictory findings have been published on this matter (3-8). Moreover, the effect of several determinants on PAI-1 levels, including some cytokines, is related to the $-6754 \mathrm{G} / 5 \mathrm{G}$ polymorphism of PAI-1 (9). The aim of this work was to study, in type 2 diabetic subjects, whether PAI-1 levels are influenced by IL-6 and, in particular, whether this relationship is genotype-dependent. Three hundred and seventy type 2 diabetic patients (162 males and 208 females, mean age $\pm \mathrm{SD}, 62.7 \pm 10.9$ years) and 374 healthy controls ( 158 males and 216 females, mean age $\pm \mathrm{SD}, 61.6 \pm 9.6$ years) matched for age and sex were studied after informed consent was obtained. This study was approved by the Ethical Committee of the INRCA Hospital. Type 2 diabetic patients were included in absence of micro- and macrovascular complications. This criterion of inclusion was applied as the presence of diabetic complications could affect "per se" the levels of both PAI-1 and IL-6. All enrolled subjects were free from statins, fibrates, aspirin, steroidal and non-steroidal antinflammatory drugs. Subjects who smoked or who had stopped smoking the previous year were classified as smokers. All subjects were Caucasians and none of them had an alcohol abuse history. Subjects were asked to abstain from any heavy physical exercise for $24 \mathrm{~h}$ before blood sampling. Fasting blood samples were collected between 8 and 10 a.m. After 10 min of centrifugation, plasma was stored at $-80^{\circ}$ C. The $4 \mathrm{G} / 5 \mathrm{G}$ PAI-1 polymorphism was analysed using the allele-specific oligonucleotide melting technique. An immunoenzymatic method for PAI-1 antigen determination (Tintelize PAI-1, Biopool, Sweden) and a commercially available immunoassay for plasma IL-6 levels (BioSource Cytoscreen human

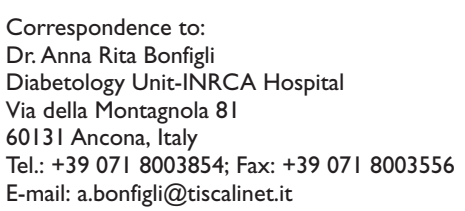

This work was supported in part by a grant from the Italian Health Ministry fund "Progetto Finalizzato FIRB code RBNE0 I8AAP_007: Identificazione di profili genomici nucleo-mitocondriali nella patogenesi di malattie comuni età-associate. Implicazioni diagnostiche e terapeutiche", and Emilia Romagna Project "ER-GenTech", FP6 EU Project "T-CIA".

Received July 12, 2005

Accepted after resubmission December 22, 2005

Prepublished online February 10, 2006 DOI 10.1160/TH05-07-0490

Thromb Haemost 2006; 95: 587-8
IL-6 UltraSensitive kit) were used. Differences between control and diabetic patients were compared by univariate analysis using Student's t test and $\chi^{2}$ test. Pearson correlation coefficients and multiple regression analysis were calculated to analyze the association between PAI-1 and IL-6 stratified by diabetic and genotypic groups controlling for other independent variables in the multiple analysis. To verify the homogeneity of regression slopes, the analysis of variance was performed when IL-6 was considered as covariate. As expected, diabetic patients showed higher percentage of hypertension and higher $\mathrm{HbAl}$, BMI, fasting glucose, fasting insulin, HOMA, triglycerides, PAI-1 $(23.11 \mathrm{x} / \div 1.95$ vs. $16.21 \mathrm{x} / \div 1.72, \mathrm{p}<0.01)$, IL-6 $(0.90 \mathrm{x} / \div 3.59$ vs. $0.58 \mathrm{x} / \div 3.08 ; \mathrm{p}<0.01)$ and lower HDL. The frequencies of the different genotypes were: $904 \mathrm{G} / 4 \mathrm{G}, 1824 \mathrm{G} / 5 \mathrm{G}$ and $1025 \mathrm{G} / 5 \mathrm{G}$ genotypes in the control group and $924 \mathrm{G} / 4 \mathrm{G}, 174$ 4G/5G and $1045 \mathrm{G} / 5 \mathrm{G}$ genotypes in the diabetic group. These genotype distributions were not different between control and diabetic groups $\left(\chi^{2}=0.20, \mathrm{df}=2, \mathrm{p}=0.90\right)$. The genotype frequencies were in Hardy-Weinberg equilibrium both in controls and cases. The allele frequencies were $48.4 \%$ for $4 \mathrm{G}$ and $51.6 \%$ for $5 \mathrm{G}$ both in control and diabetic subjects. The two-way analysis of variance highlights that the increase in PAI-1 levels in diabetic subjects was due to the effect of diabetes $(F=64.92, \mathrm{df}=1, \mathrm{p}<0.01)$ whereas no PAI-1 genotype $(\mathrm{F}=2.99, \mathrm{df}=2, \mathrm{p}=0.06)$ and PAI-1 genotype-diabetes interaction effects $(\mathrm{F}=2.26, \mathrm{df}=2, \mathrm{p}=0.11)$ were found. In addition, no PAI-1 genotype or genotype-diabetes interaction effects were detected for the other evaluated variables (data not shown). Control subjects showed no correlation between PAI-1 and IL-6 neither in the overall group nor in the three genotypes. Diversely, PAI-1 significantly correlated to IL-6 in the whole sample of diabetic subjects $(r=0.26, p<0.01)$. Stratifying by genotype, PAI-1 showed a significant correlation to IL-6 levels in the $4 \mathrm{G} / 4 \mathrm{G}$ patients $(\mathrm{r}=0.49, \mathrm{p}<0.01)$ and in the $4 \mathrm{G} / 5 \mathrm{G}$ group $(\mathrm{r}=0.28, \mathrm{p}<0.01)$. No relationship was present in the $5 \mathrm{G} / 5 \mathrm{G}$ group $(\mathrm{r}=0.02, \mathrm{p}=0.84)$. The slope $(\mathrm{b})$ and $\mathrm{SE}$ of the regression line between LnPAI-1 and LnIL-6 are as follows: for

Table I: Multiple regression analysis between IL-6 and PAI-I antigen (dependent variable) in the three genotypes in control and diabetic subjects.

\begin{tabular}{|c|c|c|c|}
\hline & $4 G / 4 G$ & $4 G / 5 G$ & $5 G / 5 G$ \\
\hline \multicolumn{4}{|c|}{ Control subjects } \\
\hline partial $r$ & -0.11 & 0.13 & -0.01 \\
\hline $\mathrm{b}(\mathrm{SE} \mathrm{b})$ & $-0.128(0.082)$ & $0.101(0.049)$ & $-0.019(0.050)$ \\
\hline$p$ value & 0.126 & 0.086 & 0.703 \\
\hline $\mathrm{R}^{2} \%$ & $23.6 \%$ & $14.0 \%$ & $17.2 \%$ \\
\hline \multicolumn{4}{|c|}{ Diabetic subjects } \\
\hline partial $r$ & 0.35 & 0.21 & 0.15 \\
\hline $\mathrm{b}(\mathrm{SE} b)$ & $0.170(0.047)$ & $0.121(0.045)$ & $0.051(0.039)$ \\
\hline$p$ value & $<0.001$ & 0.008 & 0.193 \\
\hline $\mathrm{R}^{2} \%$ & $53.2 \%$ & $20.0 \%$ & $25.0 \%$ \\
\hline
\end{tabular}


$4 \mathrm{G} / 4 \mathrm{G}, \mathrm{b}=0.263, \mathrm{SE}=0.05$; for $4 \mathrm{G} / 5 \mathrm{G}, \mathrm{b}=0.157, \mathrm{SE}=0.04$ and for $5 \mathrm{G} / 5 \mathrm{G}, \mathrm{b}=0.009, \mathrm{SE}=0.05$. Comparing the regression slopes, the analysis of variance showed that $4 \mathrm{G} / 4 \mathrm{G}$ and $4 \mathrm{G} / 5 \mathrm{G}$ slopes are statistically different from $5 \mathrm{G} / 5 \mathrm{G}(\mathrm{F}=7.15, \mathrm{df}=2, \mathrm{p}=0.001)$. Multiple regression analysis adjusting for sex, age, BMI, smoking status, hypertension, insulin resistance, triglycerides, HDL and IL-6, confirmed a significant correlation between PAI-1 and IL-6 in 4G/4G and in 4G/5G diabetic subjects, whereas no association was found in $5 \mathrm{G} / 5 \mathrm{G}$ (Table 1 ). The most important findings of this study are that the levels of PAI-1 increase with IL-6 plasma levels in diabetic patients without diabetic complications, and that this phenomenon is related to the $-6754 \mathrm{G} / 5 \mathrm{G}$ polymorphism of the PAI-1 gene. In particular, the effect of IL-6 on PAI-1 levels is evident in presence of the $4 \mathrm{G}$ allele. The knowledge of a positive association between IL-6 and PAI-1 levels demonstrates that IL-6 levels are related directly or through other inflammatory mediators to diabetic hypofibrinolysis. These observations are consistent with previous data demonstrating that the $4 \mathrm{G} / 5 \mathrm{G}$ polymorphism does not affect the basal expression of the PAI-1 gene but alters the response of the gene to environmental factors such as IL-6. Today, PAI-1 is considered a core feature of insulin resistance syndrome which is defined as a clustering of atherothrombotic traits whose underlying causes can be found in shared genetic and environmental factors. The genotype-specific effect of IL-6, the chief proinflammatory cytokine, on PAI-1 production in diabetic subjects could represent one example that evidences the interaction of the inflammation component with the genetic component in atherothrombosis. In conclusion, our findings confirm a close link between diminished fibrinolysis and atherogenic metabolic derangement evidencing the role of IL-6, in atherothrombosis.

'Anna Rita Bonfigli, 'Maurizio Marra, 'Cristina Sirolla, 'Massimo Boemi, ${ }^{2}$ Daniela Mari, ${ }^{3}$ Elisabetta Sacchi, ${ }^{4,5}$ Antonio Procopio, ${ }^{5}$ Rina Recchioni, ${ }^{6,7}$ Claudio Franceschi, ${ }^{6}$ Simona Giovagnetti, 'Roberto Testa

'Diabetology Unit, INRCA, Ancona; ' IRCCS Maggiore Hospital, Department of Internal Medicine, Milan; ${ }^{3}$ L. Sacco Hospital, Department of Immunology and Transfusion, Milan; ${ }^{4}$ Department of Molecular Pathology and Innovative Therapies, Polytechnic University of Marche, Ancona; ${ }^{5}$ Centre of Citology, INRCA, Ancona; ${ }^{6}$ Centre of Molecular Biology and Genetics, INRCA, Ancona, ${ }^{7}$ Department of Experimental Pathology, University of Bologna; Italy

\section{References}

1. Juhan-vague I, Alessi MC, Mavri A, et al. Plasminogen activator inhibitor-1, inflammation, obesity, insulin resistance and vascular risk. JThromb Haemost 2003; 1: 1575-9.

2. Pickup JC. Inflammation and activated innate immunity in the pathogenesis of type 2 diabetes. Diabetes Care 2004; 27: 813-23.

3. Dong J, Fujii S, Li H, et al.. Interleukin-6 and mevastatin regulate plasminogen activator inhibitor-1 through CCAAT/enhancer-binding protein-delta. Arterioscler Thromb Vasc Biol 2005; 25: 1078-84.

4. Rega G, Kaun C, Weiss TW, et al. Inflammatory cytokines interleukin- 6 and oncostatin $\mathrm{m}$ induce plas- minogen activator inhibitor-1 in human adipose tissue. Circulation 2005; 111: 1938-45.

5. Dawson SJ, Wiman B, Hamsten A, et al.. The two allele sequences of a common polymorphism in the promoter of the plasminogen activator inhibitor-1 (PAI-1) gene respond differently to interleukin-1 in HepG2 cells. J Biol Chem 1993; 268: 10739-45.

6. Plomgaard P, Keller P, Keller C, et al. TNF-a but not IL-6, stimulates plasminogen activator inhibitor 1 (PAI-1) expression in human subcutaneous adipose tissue. J Appl Physiol 2005; 98: 2019-23.

7. Bastelica D, Mavri A, Verdierl M, et al. Relationships between fibrinolytic and inflammatory par- ameters in human adipose tissue: strong contribution of TNF-a receptors to PAI-1 levels. Thromb Haemost 2002; 88: 481-7.

8. Panahloo A, Mohamed-Ali V, Gray RP, et al. Plasminogen activator inhibitor-1 (PAI-1) activity post myocardial infarction: the role of acute phase reactants, insulin-like molecules and promoter $(4 \mathrm{G} / 5 \mathrm{G})$ polymorphism in the PAI-1 gene. Atherosclerosis 2005; 168: 297-304.

9. Hoekstra T, Geleijnse JM, Schouten EG, et al. Plasminogen activator inhibitor-type I: its plasma determinants and relation with cardiovascular risk. Thromb Haemost 2004; 91: 861-72. 